\title{
Force-velocity characteristics of lower extremity muscles in male high-altitude climbers
}

\author{
DOI: https://doi.org/10.5114/pq.2021.109061
}

\author{
Małgorzata Stefańska', Agnieszka Dębiec-Bąk', Justyna Widelak², Anna Palczewska², Anna Skrzek', \\ Piotr Dominiak ${ }^{2}$, Wojciech Kucharski ${ }^{2}$, Katarzyna Kubasiak ${ }^{3}$ \\ ${ }^{1}$ Faculty of Physiotherapy, Wroclaw University of Health and Sport Sciences, Wroclaw, Poland \\ ${ }^{2}$ Vratislavia Medica St. John Paul II Hospital, Wroclaw, Poland \\ ${ }^{3}$ Faculty of Motor Rehabilitation, University of Physical Education in Krakow, Krakow, Poland
}

\section{Abstract}

Introduction. The study aimed to assess the force-velocity parameters of knee muscles in male high-altitude climbers and to compare the obtained results with the control group.

Methods. Overall, 31 male subjects participated in the tests. The study group comprised 12 world-renowned Polish high-altitude climbers. The control group consisted of 19 professional soldiers on active duty. The groups did not differ significantly in the average age, body weight, or height. The force-velocity parameters of knee muscles were assessed under isokinetic conditions. The velocities of $60 \%$ and $180 \%$ s were used.

Results. The values of peak torque, total work, average power, and the agonist/antagonist ratio were higher and the acceleration and deceleration times were shorter in the study group in comparison with the control group. In particular, the differences in the parameters describing the knee flexors of both limbs proved to be statistically significant. The $p$-value of the $t$-test for the dominant limb knee flexors at the velocity of $60 \%$ sas 0.0134 for peak torque, 0.0198 for total work, and 0.0019 for mean power. At the velocity of $180 \%$, the $p$ values equalled $0.0001,<0.0001$, and 0.0002 , respectively. The effect size of each test was greater than 0.92 .

Conclusions. Significant differences in force-velocity parameters of knee muscles were observed between the group of highmountain climbers and the control group. The increase in the agonist/antagonist ratio and the decrease in the acceleration and deceleration times recorded in the group of high-altitude climbers are indicative of a change in the postural and dynamic mechanisms.

Key words: acceleration time, exercise, high-altitude climbers, muscles force, peak torque, proprioception

\section{Introduction}

High-altitude climbing requires the athletes to undergo comprehensive physical and mental preparation. During expeditions, the climbers face diverse problems arising from extreme weather conditions, the length of the climbing routes, the need for gathering food supplies and camping equipment, as well as issues with communication or sense of direction. Additionally, climbers are exposed to hypoxia, since the air pressure decreases with increasing altitude, which results in lowered partial oxygen pressure in the tissues [1]. Hypoxia, associated with remaining at high altitudes, decreases the maximum exercise capacity. The impairment of endurance is caused by the decrease in partial oxygen pressure, which at 5000 meters above sea level is reduced to approximately $50 \%$ of the values recorded at the sea level. At 8000 meters above sea level, it drops to approximately $30 \%[1,2]$. The decline of endurance performance during hypoxia is determined by the scope and duration of muscle recruitment by the central nervous system [3].

The success of each expedition depends on multiple factors, such as the level of fitness and endurance of the climber, which, in turn, is conditioned by the mechanical power generated by muscle contractions [4]. It is generally accepted that the capability of performing a physical task depends on the threshold level of muscle strength and endurance $[4,5]$.
Taking into consideration the physiological limitations that arise from the performance of work at extreme altitudes, as well as the specific adaptation processes that take place in the body owing to such work, the assessment of the strength of lower extremity muscles in elite high-altitude climbers was carried out during the preparation period before a high-altitude expedition.

The professional literature indicates adaptive physiological changes concerning respiratory and cardiovascular systems that occur in high-altitude climbers [2, 6-9]. There are few publications describing force characteristics of the muscular system. Most frequently, studies refer to changes that result from remaining at extreme altitudes [10-12]. They indicate the adaptation processes of the muscular system to the conditions of hypoxia. Muscle adaptations occurring with chronic hypoxia, independent of other adaptations, positively influence muscle contractility during and after repeated contractions at high altitude [13]. Ruggiero et al. [13] imply that chronic exposure to high altitude positively affects muscle resistance to fatigue. Other studies have shown that this process remains independent of the adaptation within the central nervous system [13, 14], which will be beneficial for repetitive activity (e.g., hiking) at high altitude.

The available literature provides much research on changes in the respiratory, circulatory, nervous, and locomotor systems after exposure to high altitudes. Equally im-

Correspondence address: Małgorzata Stefańska, Faculty of Physiotherapy, Wroclaw University of Health and Sport Sciences, al. Paderewskiego 35, 51-612 Wroclaw, Poland, e-mail: malgorzata.stefanska@awf.wroc.pl 
portant are studies comparing the physiological characteristics of climbers with people who do not practise high mountain climbing, and studies of mountaineers conducted during their stay at the sea level. The identification of the specific physiological and biomechanical characteristics of elite high-altitude climbers remains to be elucidated and could provide important insights regarding the factors leading to better exercise performance preservation at high altitudes, as well as to low sensitivity to altitude sickness).

At altitudes exceeding 5000 meters above sea level, muscles undergo catabolic processes. This phenomenon may be attributed to the adaptation to hypoxia exposure $[15,16]$. The catabolism that leads to muscle wasting may also result from the negative energy balance arising from the increased energy expenditure, high level of physical activity, unbalanced diet, or loss of appetite [11]. After all other energy sources are depleted, protein is catabolized in order to remedy the deficiencies [17]. A potential factor that intensifies muscle wasting is the inhibition of the synthesis of skeletal muscle proteins and the preference for using muscle mass as the energy source during hypoxia [18].

For example, Puthon et al. [8] showed that climbers exhibited slower breathing frequency, larger tidal volume, and a larger muscle oxygenation index. These results suggest that elite climbers present some specific ventilatory and muscular responses to hypoxia, possibly because of genetic factors or adaptation to frequent high-altitude climbing.

Saul et al. [19] performed a systematic review in which they evaluated physiological, biomechanical, and psychological characteristics that simplified the ascent. The presented biomechanical studies revealed that the characteristic parameters of elite climbers were great whole-hand grip strength and endurance, postural stability with high centre-of-mass oscillations, anticipatory postural adjustments with a small Hausdorff dimension, optimized kinematic motions with a low jerk coefficient, jumping velocity higher than required, and chalky hands on clean surfaces.

In the author's own research, an attempt was made to evaluate the strength capabilities of the extensor and flexor muscles of the knee joint in elite mountain climbers and to compare the obtained results with those in the control group. It was assumed that numerous years of participation in targeted training and in many-month-long alpine expeditions would have a significant impact on the balance of antagonistic muscles and the shape of the entire characteristics also during research conducted at the sea level. Getting to know the strength capabilities of athletes would support the preparation process, thus creating conditions for optimal physical preparation. It is very important because, as it has been shown, exercise under hypoxic conditions leads to a reduction in its efficiency. Studies by Billaut et al. [20] and Smith and Billaut [21] demonstrated that a reduction in systemic $\mathrm{O}_{2}$ delivery curtailed repeated-sprint capacity via varied metabolic and neuromuscular mechanisms. For example, total mechanical work was reduced (-8\%) during ten 10 -second cycle sprints [21].

The aim of the study was to assess the force-velocity parameters of knee flexors and extensors in male high-altitude climbers in the period of no high-altitude exposition and to compare the obtained results with those in a group of soldiers on active duty.

\section{Subjects and methods}

\section{Participants}

A total of 31 male subjects participated in the tests. The study group comprised 12 world-renowned Polish high-altitude climbers. It was assumed that the control group would consist of physically active men who had not practised any sport professionally. Overall, 19 professional soldiers on active duty whose average age, body weight, and height did not statistically significantly differ from those of the members of the study group were qualified to the control group. Lack of injuries and active disease processes of the musculoskeletal system in the period of 6 months before the study and age of 35-50 years were the criteria for inclusion in the control group.

The high-altitude climbers came to the Vratislavia Medica Hospital for a health assessment within a 6-month 'training regime' that constitutes a period of preparation for an expedition. None of the group members reported active disease processes related to the musculoskeletal system, and these were also not observed in the medical examination. An individual training plan of each athlete provided physical activity 6 days per week and included elements of strength, interval, and endurance training. The nature of the exercises reflected the type of activity the athletes performed in the mountains (intervals and varying exercise loads). The preparatory period also included exercises on a climbing wall, long-distance runs (marathons and half-marathons), as well as the use of weighted vests. The control group members' profession, in turn, required their participation in regular general development exercises. The soldiers regularly underwent physical fitness and endurance tests; receiving credit for those tests was a part of their overall assessment. They also participated in long-distance runs (marathons and halfmarathons).

Prior to the measurements taking, all subjects were informed of the test procedure. The tests were carried out at the Laboratory for Functional Testing of the Faculty of Physiotherapy, Wroclaw University of Health and Sport Sciences (Poland) and at the Laboratory for Functional Diagnostics of the Vratislavia Medica St. John Paul II Hospital in Wroclaw (Poland) between July and September 2019.

\section{Research methods}

For the purpose of this study, body height and body weight were measured. Height was measured without shoes, in a standing position, to the nearest $1 \mathrm{~mm}$, with the head in the Frankfurt plane, by using an anthropometer. Weight was obtained in a standing position with standardized medical scales, with an accuracy of $100 \mathrm{~g}$.

The force-velocity parameters of knee flexors and extensors were assessed in all subjects under isokinetic conditions. Measurements with isokinetic dynamometers are characterized by high validity and reliability [22-24]; therefore, a Biodex 4 isokinetic dynamometer (Biodex Medical Systems, Shirley, USA) was used to evaluate the subjects' strength abilities. In accordance with the principles of isokinetics, the relationship between the torque generated by the muscles and the rotation angle in the joint was recorded at a constant, previously set angular velocity. A standard protocol for testing knee flexor and extensor muscles was applied [22]. The velocities of $60 \%$ s and $180 \%$ s were used. Each subject was instructed to perform 5 alternating knee flexion and extension movements with each of the loads. During each move- 
ment, the goal was to release the maximum possible power in the shortest amount of time.

\section{Statistical analysis}

The Shapiro-Wilk test served to verify the distribution of all measured parameters. In the majority of cases, the distribution was normal. The equality of variances was confirmed with Levene's test. Descriptive statistics, i.e. mean, standard deviation, and median, were calculated. The independent samples $t$-test verified the statistical significance of the average differences observed between the groups (for the parameters not characterized by normal distribution, the nonparametric Mann-Whitney $U$ test was used). Additionally, to determine the quantity of the effect of differences between the control and study groups, Hedges' $g$ test was used with a calculated confidential interval. Hedges' $g$ test values $\geq 0.8$ proved high strength of the observed effect.

\section{Ethical approval}

The research related to human use has complied with all the relevant national regulations and institutional policies, has followed the tenets of the Declaration of Helsinki, and has been approved by the Bioethics Committee of the Wroclaw Medical University (No. KB-182/2006).

\section{Informed consent}

Informed consent has been obtained from all individuals included in this study.

\section{Results}

The basic characteristics of both groups are presented in Table 1. The performed analysis did not demonstrate any significant differences in age, body weight, or height between the high-altitude climbers and the control group.

As a result of the tests, the parameters characterizing the force-velocity properties of flexors and extensors of both knees in the study group and the control group were obtained. The analysis of the results recorded at $60 \% \mathrm{~s} \mathrm{showed}$ that the peak torque, total work, average power, and the agonist/antagonist ratio were higher and the acceleration and deceleration times were shorter in the group of high-altitude climbers in comparison with the group of professional soldiers. In particular, the differences in the parameters describing the knee flexors of both limbs proved to be statistically significant. All differences with indicated statistical significance were confirmed by large effect size (Tables 2 and 3).

Furthermore, at $180 \%$ s, statistically significant differences were observed between the study group and the control group in terms of the values characterizing knee flexors (peak torque, total work, average power), as well as the values of the agonist/antagonist ratio and the deceleration times for both muscle groups. All differences with indicated statistical significance were confirmed by large effect size (Tables 4 and 5).

\section{Discussion}

In the own research, the force-velocity properties of lower extremity muscles in elite Polish high-altitude climbers were compared with the results obtained in a group of professional soldiers on active duty of similar age, body weight, and height. No significant differences regarding the knee extensors were found. However, significantly higher values of peak torque, total work, and average power measured for knee flexors, as well as a higher agonist/antagonist ratio were observed in the group of high-altitude climbers.

Table 1. Basic characteristics of the high-altitude climbers and the control group

\begin{tabular}{|l|c|c|c|c|c|c|c|}
\hline \multirow{2}{*}{ Characteristics } & \multicolumn{3}{|c|}{ High-altitude climbers } & \multicolumn{3}{c|}{ Control group } & \multicolumn{2}{c|}{$p$} \\
\cline { 2 - 8 } & Mean & $S D$ & Median & Mean & $S D$ & Median & \\
\hline Age (years) & 38.50 & 8.61 & 43.00 & 42.47 & 6.11 & 41.00 & 0.1432 \\
\hline Body weight $(\mathrm{kg})$ & 76.83 & 13.09 & 80.00 & 80.26 & 11.98 & 73.50 & 0.4596 \\
\hline Height $(\mathrm{cm})$ & 178.67 & 9.79 & 179.00 & 178.47 & 5.77 & 174.50 & 0.9452 \\
\hline
\end{tabular}

Table 2. Force-velocity parameters of extensors of both knees in the study group and the control group at $60 \% \mathrm{~s}$ and the results of the test verifying the statistical significance of the differences observed between the groups

\begin{tabular}{|c|c|c|c|c|c|c|c|c|c|c|c|}
\hline \multirow{2}{*}{\multicolumn{3}{|c|}{ Parameters }} & \multicolumn{3}{|c|}{ High-altitude climbers } & \multicolumn{3}{|c|}{ Control group } & \multirow{2}{*}{$p$} & \multirow{2}{*}{ Hedges' $g$} & \multirow{2}{*}{ $\pm 95 \% \mathrm{Cl}$} \\
\hline & & & Median & Mean & $S D$ & Median & Mean & $S D$ & & & \\
\hline \multirow{4}{*}{$\frac{n}{0}$} & \multirow{2}{*}{ Peak torque $(\mathrm{Nm})$} & $\mathrm{R}$ & 197.94 & 45.70 & 208.50 & 202.24 & 31.55 & 205.40 & 0.7582 & 0.11 & $-0.609 ; 0.838$ \\
\hline & & L & 193.92 & 42.94 & 195.75 & 192.57 & 26.54 & 192.10 & 0.9143 & -0.04 & $-0.763 ; 0.683$ \\
\hline & \multirow{2}{*}{ Total work (J) } & R & 966.21 & 159.98 & 963.70 & 1120.09 & 168.71 & 1133.20 & $0.0174^{*}$ & 0.93 & $0.171 ; 1.689$ \\
\hline & & L & 932.91 & 232.75 & 957.90 & 1058.52 & 174.91 & 1072.00 & 0.0973 & 0.63 & $-0.108 ; 1.371$ \\
\hline \multirow{6}{*}{$\frac{.}{0}$} & \multirow{2}{*}{$\begin{array}{l}\text { Average power } \\
\text { (W) }\end{array}$} & $\mathrm{R}$ & 117.43 & 27.33 & 115.15 & 130.55 & 22.75 & 127.00 & 0.1588 & 0.53 & $-0.201 ; 1.268$ \\
\hline & & L & 109.99 & 20.15 & 113.05 & 120.29 & 21.83 & 118.50 & 0.1982 & 0.49 & $-0.247 ; 1.218$ \\
\hline & \multirow{2}{*}{$\begin{array}{l}\text { Acceleration time } \\
\text { (s) }\end{array}$} & $\mathrm{R}$ & 34.17 & 15.05 & 35.00 & 44.23 & 15.74 & 40.00 & 0.0886 & 0.65 & $-0.091 ; 1.39$ \\
\hline & & L & 31.67 & 11.15 & 30.00 & 54.21 & 15.39 & 50.00 & $0.0001^{*}$ & 1.62 & $0.79 ; 2.445$ \\
\hline & \multirow{2}{*}{$\begin{array}{l}\text { Deceleration time } \\
\text { (s) }\end{array}$} & $\mathrm{R}$ & 104.17 & 80.51 & 65.00 & 205.79 & 71.28 & 220.00 & $0.0009^{*}$ & 1.36 & $0.559 ; 2.154$ \\
\hline & & L & 85.00 & 41.89 & 80.00 & 211.58 & 86.62 & 240.00 & $0.0004^{*}$ & 1.74 & $0.893 ; 2.577$ \\
\hline
\end{tabular}

$\mathrm{R}$ - right side, $\mathrm{L}$ - left side 
Table 3. Force-velocity parameters of flexors of both knees in the study group and the control group at $60 \% / \mathrm{s}$ and the results of the test verifying the statistical significance of the differences observed between the groups

\begin{tabular}{|c|c|c|c|c|c|c|c|c|c|c|c|}
\hline \multirow{2}{*}{\multicolumn{3}{|c|}{ Parameters }} & \multicolumn{3}{|c|}{ High-altitude climbers } & \multicolumn{3}{|c|}{ Control group } & \multirow{2}{*}{$p$} & \multirow{2}{*}{ Hedges' $g$} & \multirow{2}{*}{ $\pm 95 \% \mathrm{Cl}$} \\
\hline & & & Median & Mean & $S D$ & Median & Mean & $S D$ & & & \\
\hline \multirow{10}{*}{ 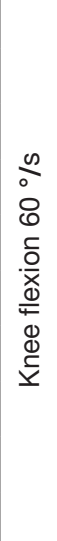 } & \multirow{2}{*}{ Peak torque $(\mathrm{Nm})$} & $\mathrm{R}$ & 116.27 & 33.27 & 114.00 & 92.32 & 17.42 & 92.00 & $0.0134^{*}$ & -0.97 & $-1.733 ;-0.209$ \\
\hline & & L & 119.21 & 29.31 & 119.85 & 87.63 & 20.58 & 89.30 & $0.0014^{*}$ & -1.30 & $-2.094 ;-0.51$ \\
\hline & \multirow{2}{*}{ Total work (J) } & $\mathrm{R}$ & 667.14 & 253.66 & 697.95 & 503.63 & 109.13 & 487.50 & $0.0189^{*}$ & -0.92 & $-1.675 ;-0.159$ \\
\hline & & L & 648.18 & 254.33 & 635.40 & 490.26 & 135.71 & 504.70 & $0.0316^{*}$ & -0.83 & $-1.585 ;-0.081$ \\
\hline & \multirow{2}{*}{$\begin{array}{l}\text { Average power } \\
\text { (W) }\end{array}$} & $\mathrm{R}$ & 83.24 & 23.25 & 85.45 & 60.94 & 13.27 & 60.80 & $0.0019^{*}$ & -1.26 & $-2.045 ;-0.47$ \\
\hline & & $\mathrm{L}$ & 83.52 & 20.62 & 86.30 & 57.47 & 16.42 & 56.90 & $0.0005^{*}$ & -1.44 & $-2.243 ;-0.631$ \\
\hline & \multirow{2}{*}{$\begin{array}{l}\text { Acceleration time } \\
\text { (s) }\end{array}$} & $\mathrm{R}$ & 40.00 & 11.28 & 40.00 & 58.49 & 18.31 & 60.00 & $0.0062^{*}$ & 1.16 & $0.377 ; 1.933$ \\
\hline & & L & 43.33 & 10.73 & 50.00 & 68.95 & 32.47 & 60.00 & $0.0167^{\star}$ & 0.97 & $0.208 ; 1.732$ \\
\hline & \multirow{2}{*}{$\begin{array}{l}\text { Deceleration time } \\
\text { (s) }\end{array}$} & $\mathrm{R}$ & 109.17 & 71.79 & 90.00 & 107.89 & 49.84 & 100.00 & 0.7000 & -0.02 & $-0.744 ; 0.701$ \\
\hline & & L & 118.33 & 86.74 & 55.00 & 136.84 & 72.73 & 120.00 & 0.2014 & 0.24 & $-0.489 ; 0.961$ \\
\hline
\end{tabular}

$\mathrm{R}$ - right side, $\mathrm{L}$ - left side

* statistically significant value $(p<0.05)$

Table 4. Force-velocity parameters of extensors of both knees in the study group and the control group at $180 \% \mathrm{~s}$ and the results of the test verifying the statistical significance of the differences observed between the groups

\begin{tabular}{|c|c|c|c|c|c|c|c|c|c|c|c|}
\hline \multirow{2}{*}{\multicolumn{3}{|c|}{ Parameters }} & \multicolumn{3}{|c|}{ High-altitude climbers } & \multicolumn{3}{|c|}{ Control group } & \multirow{3}{*}{$\begin{array}{c}p \\
0.7285\end{array}$} & \multirow{3}{*}{$\begin{array}{c}\text { Hedges' } g \\
-0.13\end{array}$} & \multirow{3}{*}{$\begin{array}{c} \pm 95 \% \mathrm{Cl} \\
-0.853 ; 0.594\end{array}$} \\
\hline & & & \multirow{2}{*}{$\begin{array}{r}\text { Median } \\
130.53\end{array}$} & \multirow{2}{*}{$\begin{array}{l}\text { Mean } \\
24.20\end{array}$} & \multirow{2}{*}{$\frac{S D}{129.30}$} & \multirow{2}{*}{$\begin{array}{l}\text { Median } \\
127.61\end{array}$} & \multirow{2}{*}{$\begin{array}{r}\text { Mean } \\
21.59\end{array}$} & \multirow{2}{*}{$\frac{S D}{125.70}$} & & & \\
\hline \multirow{10}{*}{ 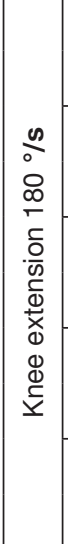 } & \multirow{2}{*}{ Peak torque $(\mathrm{Nm})$} & $\mathrm{R}$ & & & & & & & & & \\
\hline & & L & 118.09 & 14.65 & 119.40 & 121.92 & 12.48 & 120.00 & 0.4436 & 0.29 & $-0.439 ; 1.013$ \\
\hline & \multirow{2}{*}{ Total work (J) } & $\mathrm{R}$ & 1259.77 & 233.19 & 1231.05 & 1324.49 & 202.31 & 1341.65 & 0.4199 & 0.30 & $-0.425 ; 1.028$ \\
\hline & & L & 1234.88 & 309.01 & 1210.60 & 1315.61 & 199.24 & 1273.65 & 0.3821 & 0.33 & $-0.4 ; 1.055$ \\
\hline & \multirow{2}{*}{$\begin{array}{l}\text { Average power } \\
\text { (W) }\end{array}$} & $\mathrm{R}$ & 186.43 & 43.87 & 190.20 & 192.83 & 34.40 & 191.60 & 0.6539 & 0.17 & $-0.557 ; 0.891$ \\
\hline & & L & 172.30 & 28.20 & 180.88 & 182.83 & 20.67 & 179.60 & 0.2400 & 0.44 & $-0.289 ; 1.173$ \\
\hline & \multirow{2}{*}{$\begin{array}{l}\text { Acceleration time } \\
\text { (s) }\end{array}$} & $\mathrm{R}$ & 55.83 & 17.30 & 60.00 & 56.46 & 8.36 & 60.00 & 0.9831 & 0.05 & $-0.673 ; 0.773$ \\
\hline & & L & 54.17 & 19.29 & 55.00 & 61.11 & 13.67 & 60.00 & 0.2573 & 0.43 & $-0.298 ; 1.163$ \\
\hline & \multirow{2}{*}{$\begin{array}{l}\text { Deceleration time } \\
\text { (s) }\end{array}$} & $\mathrm{R}$ & 122.58 & 29.20 & 110.00 & 170.73 & 40.56 & 170.00 & $0.0000^{*}$ & 1.30 & $0.506 ; 2.09$ \\
\hline & & $\mathrm{L}$ & 110.83 & 18.32 & 110.00 & 177.22 & 37.86 & 185.00 & $0.0019^{*}$ & 2.10 & $1.193 ; 2.971$ \\
\hline
\end{tabular}

$\mathrm{R}$ - right side, $\mathrm{L}$ - left side

* statistically significant value $(p<0.05)$

Table 5. Force-velocity parameters of flexors of both knees in the study group and the control group at $180 \%$ s and the results of the test verifying the statistical significance of the differences observed between the groups

\begin{tabular}{|c|c|c|c|c|c|c|c|c|c|c|c|}
\hline \multirow{2}{*}{\multicolumn{3}{|c|}{ Parameters }} & \multicolumn{3}{|c|}{ High-altitude climbers } & \multicolumn{3}{|c|}{ Control group } & \multirow{3}{*}{$\begin{array}{c}p \\
0.0001^{*}\end{array}$} & \multirow{3}{*}{$\begin{array}{c}\text { Hedges' } g \\
-1.72\end{array}$} & \multirow{3}{*}{$\begin{array}{c} \pm 95 \% \mathrm{Cl} \\
-2.556 ;-0.877\end{array}$} \\
\hline & & & \multirow{2}{*}{$\begin{array}{r}\text { Median } \\
93.97\end{array}$} & \multirow{2}{*}{$\begin{array}{r}\text { Mean } \\
22.04\end{array}$} & \multirow{2}{*}{$\frac{S D}{103.90}$} & \multirow{2}{*}{$\begin{array}{r}\text { Median } \\
66.13\end{array}$} & \multirow{2}{*}{$\begin{array}{c}\text { Mean } \\
11.26\end{array}$} & \multirow{2}{*}{$\frac{S D}{68.80}$} & & & \\
\hline \multirow{10}{*}{ 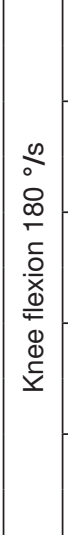 } & \multirow{2}{*}{ Peak torque (Nm) } & $\mathrm{R}$ & & & & & & & & & \\
\hline & & L & 88.09 & 19.44 & 93.35 & 65.76 & 12.43 & 64.90 & $0.0005^{*}$ & -1.44 & $-2.251 ;-0.637$ \\
\hline & \multirow{2}{*}{ Total work (J) } & $\mathrm{R}$ & 981.18 & 246.90 & 950.25 & 626.07 & 137.29 & 630.15 & $0.0000^{*}$ & -1.90 & $-2.767 ;-1.039$ \\
\hline & & L & 857.84 & 375.09 & 995.75 & 634.34 & 133.63 & 620.45 & $0.0237^{*}$ & -0.88 & $-1.636 ;-0.125$ \\
\hline & \multirow{2}{*}{$\begin{array}{l}\text { Average power } \\
\text { (W) }\end{array}$} & $\mathrm{R}$ & 138.45 & 39.16 & 141.90 & 92.82 & 20.96 & 96.70 & $0.0002^{*}$ & -1.56 & $-2.382 ;-0.741$ \\
\hline & & L & 129.64 & 40.46 & 137.70 & 91.74 & 19.36 & 91.20 & $0.0141^{*}$ & -1.30 & $-2.089 ;-0.506$ \\
\hline & \multirow{2}{*}{$\begin{array}{l}\text { Acceleration time } \\
\text { (s) }\end{array}$} & $\mathrm{R}$ & 77.50 & 32.79 & 75.00 & 90.00 & 23.01 & 85.00 & 0.2290 & 0.46 & $-0.271 ; 1.192$ \\
\hline & & L & 79.17 & 30.59 & 75.00 & 81.11 & 18.11 & 80.00 & 0.8281 & 0.08 & $-0.641 ; 0.805$ \\
\hline & \multirow{2}{*}{$\begin{array}{l}\text { Deceleration time } \\
\text { (s) }\end{array}$} & $\mathrm{R}$ & 118.33 & 41.08 & 115.00 & 130.00 & 21.14 & 130.00 & 0.3146 & 0.38 & $-0.344 ; 1.114$ \\
\hline & & L & 109.17 & 35.02 & 100.00 & 133.33 & 27.22 & 130.00 & $0.0067^{*}$ & 0.79 & $0.045 ; 1.544$ \\
\hline
\end{tabular}

$\mathrm{R}$ - right side, $\mathrm{L}$ - left side

* statistically significant value $(p<0.05)$ 
In the period preceding the tests, both groups were engaged in physical activity of a similar level. The training consisted of long-distance runs, strength workouts, and general development exercises. The higher values of force-velocity parameters recorded for knee flexors may result from the significant involvement of this muscle group in static and eccentric work during training, and then climbing. Static and eccentric work in this particular physical task, i.e. high-altitude climbing, consists in maintaining control and protecting the joint from uncontrolled movement. The static work, where the torques of muscle and external forces are balanced, and the eccentric work, where the flexed muscle is extended owing to the external forces being greater than the muscle forces, allow the antagonistic muscles to act in synergy, thus securing the postural and dynamic functions. Greater power capabilities of knee flexors in the group of highaltitude climbers were observed in particular during the analysis of the agonist/antagonist ratio (flexors to extensors). For instance, at $60 \%$, the power of flexors constituted, on average, $59.1 \%$ of the power of extensors, while in the control group, the value amounted to approximately $45 \%$.

In the group of high-altitude climbers, the analysis demonstrated significantly shorter acceleration and deceleration times, recorded irrespectively of the load for both muscle groups. With respect to the muscular activity under isokinetic conditions, during which the velocity constitutes the set, adjustable load, the acceleration time is defined as the interval between the beginning of the movement and the achievement of the set velocity; likewise, the deceleration time is defined as the final phase of the activity, where the velocity decreases from the set value to zero. The periods outside the set velocity provide valuable information on the readiness of the neuromuscular system to produce a maximum contraction [25]. They indirectly reflect the condition of the proprioceptive system. It is assumed that the shorter the acceleration and deceleration times in isokinetic measurements, the better the proprioception.

Proprioception, defined as the sense of body position, is a collection of impulses generated by muscles, tendons, articular capsules, and skin. The afferent information originating from those areas is crucial for the motor performance to be effective and safe [26]. It has been demonstrated that healthy proprioception may ensure better functioning of the system and reduce the risk for and incidence of injuries [27]. The incidence of injuries reported among high-altitude climbers is 4.2 per 1000 hours of activity [28], of which $48 \%$ result from falls [28]. This is due to the postural and dynamic mechanisms becoming insufficient under extreme conditions. Such insufficiency arises from a number of factors, including hypoxia $[29,30]$.

The unique force-velocity parameters of the muscles acting on the knees observed in the own research and recorded in high-altitude climbers when they were not exposed to extreme altitudes are indicative of specific and permanent changes in comparison with the control group. The specific nature of physical loads and the processes of adaptation to extreme altitudes cause a change in the balance of joint torques, as well as improve proprioception, which results in increased postural and dynamic control, crucial for injury prevention.

In high-altitude climbing, reaching the summit is the culmination of the expedition. Its goal is a safe return of the climbers, often achieved at the brink of exhaustion [1]. Extreme weather conditions and difficult terrain, as well as the exposure to hypoxia make high mountains a hostile environment for humans. Nonetheless, high-altitude climbing is becoming increasingly popular and accessible not only to elite athletes, but also - through commercial expeditions - to people less 'qualified' for this type of activity $[1,2,6]$.

Owing to the extreme physical effort related to climbing and the lack of opportunity to completely regenerate the body at the altitudes exceeding 5300 meters above sea level, the physical capabilities of the body decrease continuously and unnoticeably. Mizuno et al. [31] studied the adaptation of skeletal muscles to high altitudes during physical activity of various levels. Biopsies of the quadriceps and the biceps after 75-day exposure to the altitude of at least 5250 meters above sea level revealed a decrease in the average surface area of muscle fibres by $15 \%$, an increase in the average number of capillaries per surface area unit, and a stable level of muscle enzymes, irrespectively of the level of physical activity.

The unique physiological processes occurring in skeletal muscles at high altitudes are not reversed after the end of the expedition. Edwards et al. [32], while comparing the muscular activity in experienced high-altitude climbers and lowlanders, observed in a preliminary test a better mitochondrial activity and a higher concentration of non-organic phosphates in high-altitude climbers despite the fact that in the 5-month period preceding the test, none of the athletes travelled to higher altitudes or participated in any organized physical training. The physiological adaptive changes are therefore permanent. Puthon et al. [8] demonstrated significant differences in terms of the cardiac and respiratory responses to hypoxia in elite high-altitude climbers in comparison with the control group. During the tests, they observed a lower respiratory rate, higher tidal volume, and a higher muscle oxygenation rate. Near-infrared spectroscopy suggested better oxygenation of the quadriceps during exercise, which - according to the authors - is indicative of specific muscular adaptation, likely caused by cardiovascular workout during hypoxia.

The observed results suggest that the functioning of the muscular system undergoes adaptive changes in response to the channelled training of high-altitude climbers. The observed changes appear to be permanent; however, a single test, with no comparative studies conducted by other authors, is not sufficient to formulate any final claims. Therefore, it is necessary to continue the research in order to confirm the observed relationships. Conducting repetitive tests will allow the assessment and analysis of changes in force-velocity parameters throughout the entire cycle, from the preparation phase before the expedition to the restitution period after returning. The commercialization of high-altitude expeditions makes the physical preparation of the participants an issue concerning a wider group than earlier. Identifying competitors' force muscle characteristics can help in the preparatory period, e.g. by indicating the appropriate force ratio of antagonistic muscles.

\section{Conclusions}

Statistically significant higher values of torque, total work, and average power recorded for knee flexors were observed in the group of high-mountain climbers in comparison with the control group. The increase in flexors to extensors ratio and the decrease in the acceleration and deceleration times determined in the group of high-altitude climbers are indicative of a change in the postural and dynamic mechanisms.

\section{Disclosure statement}

No author has any financial interest or received any financial benefit from this research. 


\section{Conflict of interest}

The authors state no conflict of interest.

\section{Funding}

This research received no external funding.

\section{References}

1. Schneider M. Time at high altitude: experiencing time on the roof of the world. Time Soc. 2002;11(1):141-146; doi: 10.1177/0961463X02011001009.

2. Peacock $A J$. $A B C$ of oxygen: oxygen at high altitude. BMJ. 1998;317(7165):1063-1066; doi: 10.1136/bmj.317.7165. 1063.

3. Kayser B. Why is endurance performance decreased at high altitude? Schweiz Z Sportmed Sporttraumatol. 2005;53(2):54-60.

4. Brown M, Sinacore DR, Host HH. The relationship of strength to function in the older adult. J Gerontol A Biol Sci Med Sci. 1995;50(Spec Issue):55-59; doi: 10.1093/ gerona/50a.special_issue.55.

5. Brill PA, Macera CA, Davis DR, Blair SN, Gordon N. Muscular strength and physical function. Med Sci Sports Exerc. 2000;32(2):412-416; doi: 10.1097/00005768200002000-00023.

6. Basnyat B, Murdoch DR. High-altitude illness. Lancet. 2003;361(9373):1967-1974; doi: 10.1016/S0140-6736(03) 13591-X.

7. Doria C, Verratti V, Pietrangelo T, Fanò-Illic G, Bisconti AV, Shokohyar S, et al. Changes in energy system contributions to the Wingate anaerobic test in climbers after a high altitude expedition. Eur J Appl Physiol. 2020; 120(7):1629-1636; doi: 10.1007/s00421-020-04392-8.

8. Puthon L, Bouzat P, Rupp T, Robach P, Favre-Juvin A, Verges S. Physiological characteristics of elite high-altitude climbers. Scand J Med Sci Sports. 2016;26(9): 1052-1059; doi: 10.1111/sms.12547.

9. West JB. Human responses to extreme altitudes. Integr Comp Biol. 2006;46(1):25-34; doi: 10.1093/icb/icj005.

10. Alhammoud M, Morel B, Girard O, Racinais S, Sevrez V, Germain A, et al. Hypoxia and fatigue impair rapid torque development of knee extensors in elite alpine skiers. Front Physiol. 2018;9:962; doi: 10.3389/fphys.2018. 00962.

11. Dünnwald $T$, Gatterer $H$, Faulhaber $M$, Arvandi $M$, Schobersberger W. Body composition and body weight changes at different altitude levels: a systematic review and meta-analysis. Front Physiol. 2019;10:430; doi: 10.3389/fphys.2019.00430.

12. Perrey S, Rupp T. Altitude-induced changes in muscle contractile properties. High Alt Med Biol. 2009;10(2): 175-182; doi: 10.1089/ham.2008.1093.

13. Ruggiero L, Hoiland RL, Hansen AB, Ainslie PN, McNeil CJ. High-altitude acclimatization improves recovery from muscle fatigue. Med Sci Sports Exerc. 2020;52(1): 161-169; doi: 10.1249/MSS.0000000000002100.

14. Ruggiero L, Yacyshyn AF, Nettleton J, McNeil CJ. UBCNepal expedition: acclimatization to high-altitude increases spinal motoneurone excitability during fatigue in humans. J Physiol. 2018;596(15):3327-3339; doi: 10.1113/ JP274872.

15. D'Hulst G, Deldicque L. Human skeletal muscle wasting in hypoxia: a matter of hypoxic dose? J Appl Physiol. 2017;122(2):406-408; doi: 10.1152/japplphysiol.00264. 2016.

16. Favier FB, Britto FA, Freyssenet DG, Bigard XA, Benoit $H$. HIF-1-driven skeletal muscle adaptations to chronic hy- poxia: molecular insights into muscle physiology. Cell Mol Life Sci. 2015;72(24):4681-4696; doi: 10.1007/ s00018-015-2025-9.

17. Ocobock CJ. Body fat attenuates muscle mass catabolism among physically active humans in temperate and cold high altitude environments. Am J Hum Biol. 2017; 29(5):e23013; doi: 10.1002/ajhb.23013.

18. Murray AJ. Metabolic adaptation of skeletal muscle to high altitude hypoxia: how new technologies could resolve the controversies. Genome Med. 2009;1:117; doi: 10.1186/gm117.

19. Saul D, Steinmetz G, Lehmann W, Schilling AF. Determinants for success in climbing: a systematic review. J Exerc Sci Fit. 2019;17(3):91-100; doi: 10.1016/j.jesf. 2019.04.002.

20. Billaut F, Gore CJ, Aughey RJ. Enhancing team-sport athlete performance: is altitude training relevant? Sports Med. 2012;42(9):751-767; doi: 10.1007/BF03262293.

21. Smith KJ, Billaut F. Influence of cerebral and muscle oxygenation on repeated-sprint ability. Eur J Appl Physiol. 2010;109(5):989-999; doi: 10.1007/s00421-010-1444-4.

22. Davies GJ. A compendium of isokinetics in clinical usage and rehabilitation techniques. Onalaska: S \& S Publishers; 1992.

23. Drouin JM, Valovich-McLeod TC, Shultz SJ, Gansneder BM, Perrin DH. Reliability and validity of the Biodex System 3 pro isokinetic dynamometer velocity, torque and position measurements. Eur J Appl Physiol. 2004; 91(1):22-29; doi: 10.1007/s00421-003-0933-0.

24. Dvir Z. Isokinetics: muscle testing, interpretation and clinical applications. Edinburgh-New York: Churchill Livingstone; 2004.

25. Chen WL, Su FC, Chou YL. Significance of acceleration period in a dynamic strength testing study. J Orthop Sports Phys Ther. 1994;19(6):324-330; doi: 10.2519/ jospt.1994.19.6.324.

26. Hewett TE, Paterno MV, Myer GD. Strategies for enhancing proprioception and neuromuscular control of the knee. Clin Orthop Relat Res. 2002;402:76-94; doi: 10.1097/00003086-200209000-00008.

27. Aman JE, Elangovan N, Yeh I-L, Konczak J. The effectiveness of proprioceptive training for improving motor function: a systematic review. Front Hum Neurosci. 2015;8:1075; doi: 10.3389/fnhum.2014.01075.

28. Backe S, Ericson L, Janson S, Timpka T. Rock climbing injury rates and associated risk factors in a general climbing population. Scand J Med Sci Sports. 2009;19(6): 850-856; doi: 10.1111/j.1600-0838.2008.00851.x.

29. Hoshikawa M, Hashimoto S, Kawahara T, Ide R. Postural instability at a simulated altitude of $5,000 \mathrm{~m}$ before and after an expedition to Mt. Cho-Oyu (8,201 m). Eur J Appl Physiol. 2010;110(3):539-547; doi: 10.1007/ s00421-010-1530-7.

30. Stadelmann K, Latshang TD, Lo Cascio CM, Clark RA, Huber R, Kohler M, et al. Impaired postural control in healthy men at moderate altitude (1630 m and $2590 \mathrm{~m})$ : data from a randomized trial. PLoS One. 2015;10(2): e0116695; doi: 10.1371/journal.pone.0116695.

31. Mizuno M, Savard GK, Areskog N-H, Lundby C, Saltin B. Skeletal muscle adaptations to prolonged exposure to extreme altitude: a role of physical activity? High Alt Med Biol. 2008;9(4):311-317; doi: 10.1089/ham.2008.1009.

32. Edwards LM, Murray AJ, Tyler DJ, Kemp GJ, Holloway CJ, Robbins PA, et al. The effect of high-altitude on human skeletal muscle energetics: P-MRS results from the Caudwell Xtreme Everest expedition. PLoS One. 2010; 5(5):e10681; doi: 10.1371/journal.pone.0010681. 